\title{
Aprendendo a ler, aprendendo a escrever história: O olhar das crianças na produção do conhecimento histórico
}

Maria Auxiliadora Moreira dos Santos SCHMIDT

Tânia Maria Figueiredo Braga GARCIA ${ }^{I}$

RESUM0

Relata resultados de projeto de extensão e de intervenção desenvolvido com crianças de 9-10 anos de idade, que cursam a terceira série do Ensino Fundamental, e professoras que atuam em municípios da Região Metropolitana de Curitiba, Estado do Paraná (Brasil), com o objetivo de discutir e propor alternativas para o ensino da História, disciplina curricular que tem sido enfatizada como aquela que mais propriamente se destina à formação do cidadão. Essa perspectiva pode ser claramente identificada nos textos oficiais de orientação curricular produzidos e divulgados pelo Ministério da Educação brasileiro, em particular nos Parâmetros Curriculares Nacionais, quese constituem em referências para a elaboração de propostas curriculares nos estados e municípios. Mas, se a cidadania política tem encontrado espaço, a idéia de cidadania social que inclui os conceitos de igualdades, de justiça, de diferenças, de lutas e de conquistas, de compromissos e de rupturas ainda é pouco fortalecida nas propostas. 0 projeto Recriando Histórias volta-se à necessidade de repensar os próprios conteúdos da História escolar de forma a tomar as questões da cidadania como objeto deensino paracrianças e jovens em escolarização, elaborando propostas que articulem a História da Cidade com a perspectiva da formação da consciência histórica, tendo os Direitos Humanos como categoria estruturadora. Nesse projeto, a partir da pesquisa, identificação e análise de documentos em estado de arquivo familiar (Artières), realizada pelos alunos sob a orientação das professoras, estruturam-se atividades por meio das quais as crianças produzem materiais que são incorporados na elaboração de livro didático, revelando o seu olhar sobre elementos da História e contribuindo, por meio de suas narrativas, para a produção do conhecimento a ser ensinado nas aulas de História.

Palavras-chave: ensino de história, cidadania, arquivos familiares, conciência histórica..

1 Professoras e pesquisadoras do PPGE em Educação da UFPR. Bolsistas Cnpq. Projeto financiado pelo Cnpq e Fundação Araucária (Endnotes) 


\section{Introdução}

0 Ensino da História no Brasil, após sua introdução oficial nos programas escolares em 1931, passou por diferentes processos de transformação. Na segunda metade da década de 1990, o Ministério da Educação elaborou e divulgou os Parâmetros Curriculares Nacionais, documento que sugere os conteúdos a serem privilegiados nas séries iniciais do ensino fundamental. No caso específico da História, indicam a relevância de se trabalhar conteúdos cuja natureza contribua para a formação da cidadania. É importante lembrar que essas mudanças propostas apenas lentamente chegam às escolas dos sistemas de ensino, particularmente às redes municipais responsáveis pelas séries iniciais de escolarização. Por outro lado, dificuldades específicas são apontadas pelos professores que, em número significativo, não são licenciados. Formação, condições objetivas de trabalho e inadequação de materiais didáticos comprometidos com a formação para a cidadania e para os direitos humanos têm sido apontados pelos docentes e pelos técnicos de Secretarias Municipais da Educação como problemas e, nessa direção, foi organizado o Projeto Recriando Histórias para assessorar municípios da região metropolitana de Curitiba, na forma de atividades de extensão e pesquisa da Universidade Federal do Paraná.

Resultados desse trabalho foram apresentados em artigos (Schmidt e Garcia, 2001) e em eventos científicos $(2001,2003,2004)^{1}$, descrevendo mais detalhadamente suas atividades em dois Municípios - Pinhais e Campina Grande do Sul - e analisando diferentes dimensões que se articulam no contexto do Projeto, entre elas a seleção de conteúdos de ensino de História e a discussão curricular, a formação continuada de professores, a pesquisa no ensino e a produção de manuais didáticos. Neste artigo, são apresentados resultados da investigação realizada no Projeto Recriando Histórias de Campina Grande do Sul, particularmente no que se refere à análise de narrativas históricas produzidas pelas crianças que participaram das atividades de elaboração e de uso de um manual didático produzido especialmente com e para as escolas municipais.

1 Em 2001, em Santiago de Compostela: Recriando Histórias: a produção de materiais de ensino a partir da História Local; em 2003, na ANPEd: Contribuições para a discussão no campo da Didática: análise do Projeto Recriando Histórias; em 2004, em Ambleside, UK: Teaching history from documents in the family archives: a social experiment with brazilian children. 
Uma primeira referência teórica se localiza nas contribuições de Freire (1987) que permitem afirmar que os conteúdos dos processos pedagógicos, no ensino e na aprendizagem, devem ser constituídos a partir da identificação, nos contextos locais e também em âmbitos mais amplos, das diversidades e desigualdades que compõem a realidade social, e que se expressam e são compreendidas de diferentes formas pelos sujeitos. Do ponto de vista didático, isso impõe a necessidade de repensar os conteúdos e organizar o ensino com os alunos e professores, numa dimensão significativa para todos eles.

A segunda referência, do campo da historiografia, está relacionada à concepção que entende 0 ensino de História como 0 estudo da experiência humana no tempo, na perspectiva de Thompson (1981). Essa perspectiva permite dar aos conteúdos de ensino um tratamento temático, na direção de recuperar 0 sentido das experiências pessoais e coletivas que dizem respeito aos temas e assim, contribuir para a formação de identidades individuais e coletivas. Trata-se de uma forma de abordar a aprendizagem, a construção e a compreensão do conhecimento histórico, a partir de proposições que tenham a ver com os interesses dos alunos, suas aproximações cognitivas e afetivas, sua vivência cultural, com as possibilidades de desenvolver atividades vinculadas diretamente com a vida cotidiana entendida como expressão concreta de problemas mais amplos, que envolvem, desde a realidade mais próxima como a mais ampla.

Uma outra referência que embasa 0 projeto sustenta-se nos estudos relacionados à ampliação do conceito de documentos históricos e ao uso de fontes no ensino de história, Com relação ao primeiro aspecto, o trabalho de Artières (1998) introduz a importância dos documentos guardados "em estado de arquivo familiar", que são mantidos cotidiana e silenciosamente pelos indivíduos, tais como notas fiscais, comprovantes e escrituras de propriedades, listas de tarefas, jornais, revistas e fotografias. No que se refere ao uso de documentos no ensino de história, alguns resultados já computados desse projeto indicam que a lida das crianças com os documentos guardados pelas suas ou outras familias, tem um forte componente estimulador de sentimentos de empatia em relação ao passado. A importância desse sentimento na formação das idéias históricas de crianças e jovens foi analisada em trabalhos como os de Ashby (2003).

Este conjunto de referências conduziu a uma opção metodológica em 
que os professores foram estimulados - e preparados - para o trabalho com documentos históricos, especialmente os que se encontram em arquivos familiares, e estimulados a produzirem suas interpretações acerca do passado, a partir da construção de narrativas históricas.

\section{Metodologia}

Do ponto de vista metodológico, o projeto levou em consideração a necessidade de participação de professores e alunos como sujeitos capazes de atuar e produzir conhecimento. Essa perspectiva trouxe para as investigadoras a necessidade de estruturar atividades que possibilitassem, por um lado, um alto grau de participação dos sujeitos e, de outro, abrissem espaço para a produção de novos conhecimentos sobre o ensino e sobre materiais didáticos.

Assim, na perspectiva de tomar os conteúdos culturais como referência no processo de ensino e aprendizagem e com o objetivo de contextualizar as tarefas de aprendizagem dentro da cultura experiencial dos sujeitos, mediante uma participação ativa dos alunos na determinação desses conteúdos, foi estruturada a primeira fase do projeto: um processo de "captação de conteúdos" a serem ensinados, por meio de um conjunto de atividades voltadas à coleta de documentos guardados "em estado de arquivo familiar", desenvolvidas por alunos e professores de terceira série, com faixa etária entre 9 e 10 anos de idade, atividade estas pensadas e planejadas como estratégias e recursos de ensino. Assim, alunos e professores desenvolviam, nas salas de aula, atividades didáticas sobre os temas pesquisados, analisando documentos iconográficos e escritos, discutindo e comparando depoimentos colhidos, buscando articular seus conhecimentos prévios (Barca, 2004) às informações e aos dados coletados e, portanto, construindo coletivamente um certo tipo de conhecimento sobre aspectos da História, a partir da problematização das fontes encontradas. A relação entre alunos e professores com as diferentes fontes propiciou uma articulação entre a micro-história mais identificada com aspectos da vida familiar e comunitária e a macro-história da localidade e do país.

0 conjunto de materiais produzidos a partir das atividades nas salas de aula - textos, desenhos, histórias em quadrinhos, cartazes, entrevistas - constituiu um acervo de narrativas produzidas pelos alunos e professores que, devidamente 
organizado por meio de processos de seleção e classificação, tratado epistemologicamente e didaticamente e articulado a outros materiais, resultantes de outras atividades de pesquisa histórica em bibliotecas, arquivos e museus, viria a ser utilizado na segunda fase do projeto: a elaboração de um livro didático para uso nas escolas, colocando em prática alguns princípios na produção e de uso de manuais didáticos que se diferenciam daqueles tradicionalmente produzidos para as escolas brasileiras.

0 tratamento epistemológico do acervo foi fundamentado no quadro referencial da própria História, segundo os trabalhos de Lee (2003). Para esse autor, a educação histórica sustenta-se no desenvolvimento da relação que os sujeitos estabelecem com as idéias constitutivas da própria natureza da História, tais como as fontes, narrativas e explicações históricas, bem como dizem respeito aos próprios conteúdos e conceitos históricos, tais como imigração, religião, trabalho, entre outros.

0 resultado do trabalho desenvolvido com as crianças e professoras pode ser observado no quadro a seguir (ver quadro 1):

Quadro 1: Resultados da produção feita com os alunos.

\begin{tabular}{|c|c|c|c|c|}
\hline Conceitus sulstantivos & Documentos utilizados & Atividades & Idéias de Segunda & Quantidades \\
\hline Patrimônio & $\begin{array}{l}\text { Arcuitetura } \\
\text { Fotografia } \\
\text { Depoimentos orais }\end{array}$ & $\begin{array}{l}\text { Visitas de estudo, } \\
\text { entrevistas, produção } \\
\text { de texto iconográfico }\end{array}$ & $\begin{array}{l}\text { Evidência } \\
\text { Fontes orais e } \\
\text { iconográficas } \\
\text { Inaginação histórica } \\
\text { Temporalidade. } \\
\text { Narrativas }\end{array}$ & 06 \\
\hline Topononímia & $\begin{array}{l}\text { Paisagens urbanase } \\
\text { nirais } \\
\text { Depoimentos }\end{array}$ & Visitas de estudo & $\begin{array}{l}\text { Mudançase } \\
\text { permanências }\end{array}$ & 06 \\
\hline Lendase mitos locais & & Entrevistas & $\begin{array}{l}\text { Imaginação } \\
\text { histórica; empatia } \\
\text { Fontes orais }\end{array}$ & 01 \\
\hline Práticas alimentares & $\begin{array}{l}\text { Documentos } \\
\text { escritos:cadernos de } \\
\text { receitas }\end{array}$ & $\begin{array}{l}\text { Análise de } \\
\text { documento escrito }\end{array}$ & $\begin{array}{l}\text { Evidência } \\
\text { Narrativa }\end{array}$ & 02 \\
\hline
\end{tabular}




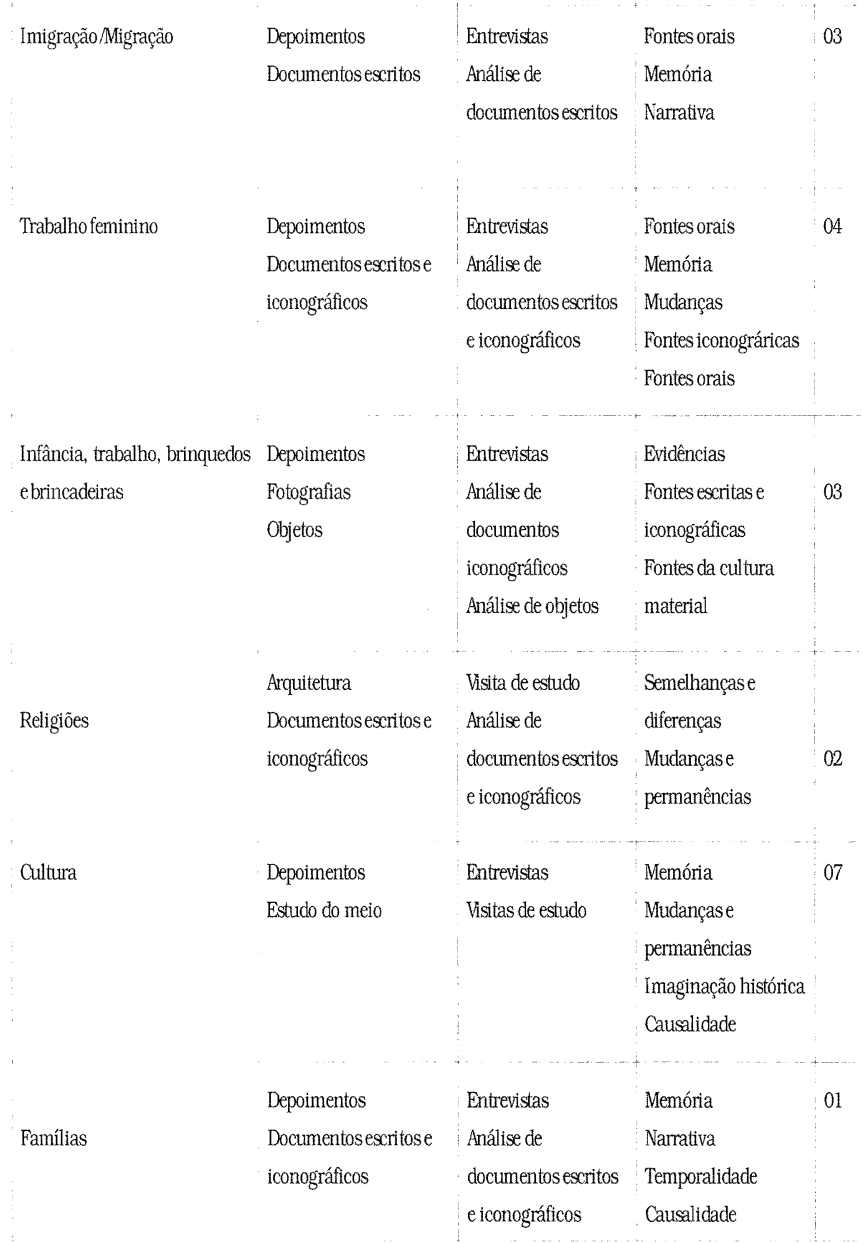

A terceira fase do projeto consistiu no acompanhamento dos professores quanto à forma de utilização do livro didático no desenvolvimento das aulas com outras turmas de terceira série. Nessa etapa foram discutidas e avaliadas a proposta de organização didática do trabalho e a forma como as atividades foram articuladas aos conteúdos do livro, bem como as atividades produzidas pelos alunos, sobre cada um dos temas.

Tomando como material empírico os resultados desse trabalho e apoiando- 
se teoricamente nos estudos realizados por Prost (2001) Cooper (2003), Barca e Gago (2004), Husbands (2003), Lee (2003), e Ashby (2003), uma quarta fase da investigação consistiu na análise das narrativas produzidas pelos alunos das escolas municipais, cujos resultados estão sendo privilegiados neste texto e serão apresentados a seguir.

\section{Análises}

Para a análise das narrativas produzidas pelos alunos foi elaborado um quadro de referência categorial a partir dos pressupostos teóricos assumidos. Tomando como referência os elementos apontados no quadro construído (Schmidt e Garcia, 2005), foram examinadas as narrativas produzidas pelos alunos em duas situações: durante a elaboração do manual didático e, posteriormente, a partir do uso do manual em sala de aula.

\subsection{Narrativas produzidas pelos alunos durante a elaboração do manual didático.}

Durante a produção do manual didático, foram realizadas várias atividades em que as crianças pudessem expressar suas conclusões sobre 0 conhecimento histórico, após o trabalho com os documentos. Uma destas atividades foi denominada de "A História no Olhar das Crianças", em que as professoras utilizavam diferentes estratégias para estimular a produção de idéias e a construção de narrativas históricas pelos alunos. Com o objetivo de examinar a produção das crianças, foi selecionada uma destas atividades incorporadas ao manual didático, destacando-se aqui duas narrativas produzidas por alunos de diferentes escolas. Um dos temas sugeridos no currículo da escola era "Gentes e Famílias da Localidade", sendo que um dos conteúdos relacionados foi "A origem das famílias da localidade". Para trabalhar este conteúdo, as professoras seguiram um mesmo roteiro: 1. Reflexões com os alunos destacando a importância da história de suas famílias para a localidade; 2. Problematização do tema, indagando oralmente: quem faz parte de sua família? Todas as famílias são iguais? Tiveram a mesma história? Qual a origem de sua família? 3. Trabalho com a certidão de nascimento dos alunos, para confirmar alguns dados a 
partir deste documento; 4. Desenho de sua família; 5. Comparação entre os diferentes desenhos das crianças; 6. Desenho, pela criança junto com os pais, da árvore genealógica de sua família, comentados posteriormente em aula; 7. Entrevista de cada criança com seus pais para saber de onde veio a sua família.

As entrevistas realizadas foram comentadas em aula e, como atividade final, foi solicitado que cada aluno escrevesse uma narrativa sobre a história de sua família. A análise das narrativas de dois alunos está apresentada a seguir.

\section{A - Narrativa de Felipe Gueno}

No final do século XIX meu trisavô veio para o Brasil de navio ainda criança, fivou morando em Campina Grande do Sul em terras doadas pelo governo, onde casou-se com minha trisavô que se chamava Maria Luiza Canestraro. . Inicialmente eles trabalharam na lavoura com erva-mate e finalmente abriram uma serraria. Tiveram como um dos filhos meu bisavô Felix Ferrarine que casou-se com minha bisavó Páscoa Coradim, que tiveram como filha minha Avó Gemma Coradim mãe de meu pai Amarildo Gueno.Eu Felipe Gueno,faço parte desta grande familia, que nesta cidade se fixou e hoje tem uma situação financeira estável.

\section{B - Narrativa de Wesley Botelho}

\section{A história do meu bisavô}

O meu bisavô nasceu do casamento de um português com uma escrava. Ele tinha uma vida boa mas depois que seu pai morreu seu tio resolveu adotar ele. Só que ele era tratado como empregado sofrendo muito. Com doze anos resolveu ir emborae acabou conhecendo sua esposa. Quando soube que sua mãe morreu, até pensou em ir atrás da sua herança e nem sua família procurou ele para dividir a fortuna. Então essa época, ele veio morar aqui em Campina Grande do Sul e viveu aqui até morrer. Tem até uma rua que se chama José Botelho Filho em sua homenagem.

Tomando como referência as categorias definidas, foi possível localizar os seguintes elementos nas narrativas produzidas pelos dois alunos (ver quadro 2 a seguir): 
Quadro 2: Resultados da análise de narrativas produzidas durante a produção do manual didático.Tomando como referência as categorias definidas, foi possível localizar os seguintes elementos nas narrativas:

\begin{tabular}{|l|l|l|}
\hline Categorias de análise & Aluno Felipe Gueno & Aluno Wesley Botelho \\
\hline Causalidade & $\begin{array}{l}\text { "meu trisavô .fixou moradia em C.G.S. } \\
\text { em terras doadas pelo governo, onde } \\
\text { casou-se..." }\end{array}$ & $\begin{array}{l}\text { 0 meu bisavô nasceu do casamento de um } \\
\text { português com uma escrava" } \\
\text { "seu tio resolveu adotar ele.Só que era tratado } \\
\text { como empregado sofrendo muito". }\end{array}$ \\
\hline Continuidade & $\begin{array}{l}\text { 0 texto da narrativa é estruturado numa } \\
\text { perspectiva de continuidade que começa } \\
\text { com seu trisavô e termina com ele } \\
\text { próprio. }\end{array}$ & $\begin{array}{l}\text { Não privilegia uma continuidade, mas esta é } \\
\text { construída a partir da necessidade que tem de }\end{array}$ \\
explicar o que aconteceu.
\end{tabular}

\subsection{Análise das narrativas produzidas a partir do uso do manual didático}

Após a produção do manual didático, o trabalho nas aulas de História passou a ser planejado de forma a articular a realização de outras atividades ao texto didático, como os pequenos livros que foram produzidos pelos alunos. Um exemplo é o trabalho feito com o tema "Os nomes de Campina Grande do Sul" no qual a professora tinha os objetivos de que as crianças compreendessem o significado de alguns conceitos como vila, distrito, freguesia e município; e que descrevessem as 
mudanças de nome ao longo do tempo. Para iniciar o trabalho, a professora pediu que as crianças desenhassem, propondo a seguinte atividade: "VILA, FREGUESIA, DISTRITO, MUNICÍPI0: o que eu penso sobre isso".

Realizada esta investigação inicial, o segundo passo consistiu na apresentação pela professora de uma problematização: Como se deu o início do povoamento de nossa localidade? Os alunos foram apresentando suas idéias a respeito do conteúdo e a professora foi anotando no quadro os elementos apresentados por eles. A etapa seguinte foi a construção de uma linha do tempo em que os diferentes nomes que a localidade recebeu ao longo da sua história foram sendo situados. 0 terceiro passo foi 0 trabalho com manual didático e com outros documentos trazidos pela professora e pelos alunos, com o objetivo de localizar temporalmente as mudanças de nome da localidade e complementar a linha de tempo. Após essas intervenções da professora, os alunos produziram pequenos livros com o título "Os nomes do nosso Município Campina Grande do Sul". 0 texto feito por Fabiana Mocellin ( 9 anos), acompanhado por desenhos, é o seguinte:

Em 1666 nasce um pequeno povoado "Arraial Queimado", um lugar com poucos habitantes e poucas casas. Em 1873, foi criada a Freguesia de Campina Grande, um lugar que passava a ter a presença de um padre. Em 1889, mudou para Villa de Campina Grande, um lugar que ficava a sede do governo. Em 1890, José Marques de Guimarães troca o nome por Vila Glycério. Em 1891 os moradores foram às ruas e pediram a mudança de nome que voltou a ser Villa de Campina Grande. Em 1939 o Município foi extinto e a região passou a ser DISTRITO, em parte de Piraquara e em parte de Bocaiúva do Sul. Um distrito não tem liberdade para fazer as leis. Em 1943 o nome mudou para Timbu, palavra de origem Tupiguarani. Em 1951, a região volta a ser Município, ainda com o nome de Timbu. Em 1956 a população pediu e o governador assinou a Lei 2593 dando 0 nome ao Município de Campina Grande do Sul.

É necessário destacar que os alunos produziram duas narrativas - uma escrita e outra por meio de seus desenhos. A análise da narrativa escrita produzida pela aluna Fabiana permite apontar os seguintes elementos em relação ao quadro de referência categorial (ver quadro 3 a seguir): 
Quadro 3: Resultados da análise de narrativa produzida a partir do uso do manual didático.

\begin{tabular}{|l|l|}
\hline Categorias de análise & Aluna Fabiana Mocellin \\
\hline Causalidade & "Em 1943 o nome mudou para Timbu, palavra de origem tupiguarani." \\
\hline Continuidade & $\begin{array}{l}\text { 0 texto da narrativa é estruturado numa perspectiva de continuidade, aspecto que foi } \\
\text { enfatizado no trabalho da professora pela construção da linha do tempo. }\end{array}$ \\
\hline Mudança & $\begin{array}{l}\text { Indica as mudanças do nome a partir das mudanças na estrutura administrativa e no } \\
\text { desenvolvimento da localidade. Os desenhos marcam os aspectos de mudança por meio da } \\
\text { quantidade de casas, pelo aparecimento de elementos como a Igreja (em 1873) e como a } \\
\text { Prefeitura e a Escola na praça (em 1956) }\end{array}$ \\
\hline $\begin{array}{l}\text { Incorporação de novos } \\
\text { elementos aos } \\
\text { conhecimentos prévios } \\
\text { dos alunos }\end{array}$ & $\begin{array}{l}\text { Incorporação de cronologia (pela inclusão das datas que marcaram as mudanças de } \\
\text { nome); incorporação dos conceitos de vila, freguesia, distrito e município, associando-os a } \\
\text { modificações na estrutura administrativa da localidade (como a presença do padre na } \\
\text { Freguesia) e a impossibilidade de fazer suas próprias leis (como Distrito). }\end{array}$ \\
\hline $\begin{array}{l}\text { Utilização de conceitos } \\
\text { temporais }\end{array}$ & $\begin{array}{l}\text { Cronologia- a estruturação dos desenhos obedece a uma ordem cronológica na qual vai } \\
\text { mostrando os sucessivos momentos da história da localidade. A relação passado-presente } \\
\text { aparece na forma como os desenhos explicam a participação dos moradores na mudança } \\
\text { do nome da cidade, em passeata com cartazes, forma com a qual a aluna convive em sua } \\
\text { experiência cultural. A simultaneidade está presente na compreensão de que ao se tornar } \\
\text { Distrito a localidade passa a pertencer a outros municípios e perde a liberdade de fazer as } \\
\text { próprias leis. }\end{array}$ \\
\hline $\begin{array}{l}\text { Formas de estruturação } \\
\text { da narrativa }\end{array}$ & $\begin{array}{l}\text { Predomina a dimensão linear e cronológica dos acontecimentos. Narrativa do tipo "relato", } \\
\text { onde as relações entre os acontecimentos são mostradas por ordem de sucessão. Personifica } \\
\text { as ações relacionando-as a personagens da história oficial (o Governador), mas também } \\
\text { aos moradores da localidade (os habitantes vão para as ruas pedir a mudança de nome). }\end{array}$ \\
\hline
\end{tabular}

\section{Conclusões}

A análise dos materiais produzidos permitiu algumas conclusões sobre as mudanças que ocorreram na forma de alunos e professores se relacionarem com o conhecimento histórico, com as fontes documentais e com a metodologia de trabalho com as fontes, resultando numa ênfase à produção de narrativas históricas pelos próprios alunos. A produção de materiais de ensino, particularmente do livro "Recriando Histórias de Campina Grande do Sul", resultou em uma descoberta efetiva por parte de alunos, professores e comunidade, de que suas histórias são importantes e de que eles também são sujeitos da História.

É importante ressaltar que o projeto não ocorreu de forma pontual, mas ao longo de um período longo de trabalho. Os resultados aqui apresentados foram analisados a partir da intervenção didática feita pelos professores e mostram, portanto, alguns aspectos avaliados dentro de um processo. Nesse processo de produção de narrativas, os alunos puderam confrontar o que 
aprendiam na sala de aula com suas próprias estruturas de compreensão histórica, comparando os diferentes documentos com suas experiências anteriores, inclusive as escolares.

A partir da intervenção didática realizada pelos professores, as crianças apresentaram nas suas narrativas uma compreensão restrita do passado (Barca e Gago, 2004), em que revelam um entendimento global das mensagens e tentam reformular as informações contidas nos documentos, mas centram-se em um único indicador. Contudo, essa compreensão restrita já aponta indícios de uma compreensão global, pois em alguns momentos conseguem identificar diferenças entre as informações que recebem e que se acham nos documentos, fazendo interpretações sobre a relação passado-presente, bem, como reformulam suas próprias informações.

Pode-se afirmar, concordando com Barca e Gago (2004), que quando essas crianças procuram construir explicações para situações específicas do passado à luz de suas próprias experiências, elas já estão revelando um esforço de compreensão histórica.

Destaca-se, ainda, que a partir da pesquisa, identificação e análise de documentos em estado de arquivo familiar, realizada pelos alunos sob a orientação dos professores, foram estruturadas atividades por meio das quais as crianças produziram materiais que foram incorporados na elaboração de um manual didático, revelando o seu olhar sobre elementos da História e contribuindo, por meio de suas narrativas, para a produção do conhecimento a ser ensinado nas aulas de História.

\section{Referências}

ARTIÈRES, P. (1998). Arquivar a própria vida. Estudos Históricos: arquivos pessoais. Rio de Janeiro: Fundação Getúlio Vargas, 21, 9-34.

ASHBY, R. (2003). The concept of Historical Evidence: Curriculum demands and children's understandings. In Barca, I. (org). Educação Histórica e Museus. . Actas das 2as. Jornadas Internacionais de Educação Histórica (37-55). Braga: Cied: IEP/ Universidade do Minho.

BARCA, I. (2003). Seminário realizado na Universidade. Federal do Paraná. Curitiba (Apontamentos). 
BARCA, Isabel; Gago, Marilia (2004). Usos da narrativa em História. In. MELO, Maria do Céu/LOPES, José Manuel (orgs). Narrativas bistóricas e ficcionais. Recepção e produção para professores e alunos (29-39). Actas. Centro de Investigação em educação. Instituto de Educação e Psicologia. Braga: Universidade do Minho.

COOPER, H. (2002) Didática de la Historia em la educacion infantil e primaria. Ministério de Educacion Cultura y Deporte/Centro de Investigacion Educativa-CIDE/ Ediciones Morata.

FREIRE, P. (1987). Pedagogia do Oprimido. Rio de Janeiro: Paz e Terra.

HUSBANDS, Chris. (2003) What is History teaching? Language, ideas and meaning in learnig about the past. Buckingham-Philadelphia: Open University Press.

LEE, Peter (2003). "Nós fabricamos carros e eles tinham que andar a pé. Compreensão da vida no passado. ("We're making cars, and they just had to walk": understanding people in the past (19-36). In BARCA, Isabel (org). Educação Histórica e museus. Actas das 2as. jornadas internacionais de educação histórica. Braga: Universidade do Minho.

MELO, M.C. (2001) 0 conhecimento tácito substantivo histórica dos alunos - no rasto da escravatura. Barca, I. Perspectivas em Educação Histórica. (43-53) Braga: Universidade. do Minho.

OSSANA, E.(1994) Una alternativa en la ensenanza de la Historia: el enfoque desde lo local, lo regional. In. VAZQUES, J. Enseñanza de la Historia. Colección Interamer. Buenos Aires.

PROST, Antoine (2001) Doce Leciones sobre la Historia. Valencia (ES): Ediciones Frónesis/Catedra Universitat de Valéncia..

SCHMIDT, M.A.; Garcia, T.B. (2003) Recriando Historias de Campina Grande do Sul. Prefeitura Municipal de Campina Grande do Sul/Universidade Federal do Paraná.

SCHMIDT, M.A.; Garcia,T.B. (2005). Bulding bistorical narratives based on documents from the family archives: a social experiment with brazilian children. Trabalho apresentado no FIRST CONGRESS - ISCAR . Sevilha, ES. (no prelo).

THOMPSON, E. (1981) A miséria da teoria. Ou um planetário de erros. Uma crítica ao pensamento de Althusser. Rio de Janeiro: Zahar. 


\section{Learning how to read, learning how to write history: the look of the infants in the output of the historical knowledge}

\section{ABSTRACT}

This paper shows the results of the research and intervention with students (910 years old) of public fundamental schools, and teachers of the metropolitan area of Curitiba, in the state of Paraná, Brazil, as an activity of the project "Recreating Histories", developed as a collaborative work between the Federal University of Paraná and the council of the Cities, having as the main objective the improvement of historical contents for the earlier grades students. The purpose of the research was to identify contents and build new methods of History teaching appropriate to a program which main goal is the study of the experience of common people (Thompson), in the perspective of Human Rights. In the development of the research the methods of Local History were used as well as the modern perspective of the historical document. The concept of private archive (Artières) was also used for targeting the resources and for the production of school activities, which were incorporated in a didactic book, showing children's perspectives about History elements and their contribution to the production of historical knowledge to be taught in History classes.

Key-words: history teaching; citizenship, local history, historical knowledge. 